Interactive comment on "Recent acceleration of Denman Glacier (1972-2017), East Antarctica, driven by grounding line retreat and changes in ice tongue configuration" by Bertie W. J. Miles et al.

Anonymous Referee \#3

Received and published: 22 September 2020 


\section{Comments to "Recent acceleration of Denman Glacier (1972-2017), East Antarctica, driven by grounding line retreat and changes in ice tongue configuration." by Miles et al.}

September 22, 2020

\section{General comments}

In this manuscript, Miles et al reconstructed the migration of ice front and the evolution of the velocity field of Denman Glacier, Aurora subglacial basin, East Antarctica based on satellite images from 1962 to 2018 . The ice sheet model Ua is then implemented to study the potential drivers of the widespread acceleration of Denman glacier between 1972 and 2009.

The manuscript is well written and easy to follow. Reconstruction of historical evolution of ice flow as well as the calving events is valuable for modellers to verify and improve the physical processes and parameterizatons in the ice sheet models. While the observation work is fascinating, I find the numerical modeling experiments not enough to 
support the conclusions. The authors conclude that grounding line retreat, ice tongue thinning and unpinning from the pinning point are necessary to rebuild the acceleration over the glacier, and therefore emphasize the impact of ocean warming and calving events to the dynamics of Denman glacier. The three experiments are thinning the ice shelf, adjusting the bedrock elevation near the grounding line, and altering the bedrock elevation of the pinning point. Changing the bedrock elevation to mimic the same unpinning seen by the ice fractures is very tricky, since it affects the entire ice geometry for the wrong reasons. I think the ice sheet model Ua is capable to simulate what you want to investigate, but I suggest adaptations of the simulations (see specific comments). Therefore, I suggest a major change of the manuscript for the simulation sections.

\section{Specific comments}

- Line 15: It's mentioned several times in the manuscript the potential instability due to the retrograde slope. I think it could help the readers to understand the configuation better if the authors show in one of the figures (e.g. Fig. 1) a transection along the flow line to show the geometry.

- Line 17: ice tongue structure $\rightarrow$ ice-tongue structure. Please check the use of the hyphens over the manuscript.

- Line 21: In this manuscript, 'grounding line retreat' is taken as a driver of the recent change of Denman glacier. This is a confusing expression, grounding line retreat is a change (due to mass loss at the grounding line) rather than a driver of change. For example, continuous grounding line retreat on the retrograde slope is a result of ice shelf thinning and increasing ice flux at the grounding line, not the other way around. 
- Line 30: Is 'Wilkes Land' here and also in Line 49 the same region as 'Aurusa Subglacial Basin'? If so, use one of them to avoid confusion.

- Line 68: mention also the conclusions section.

- Line 127-129: The authors predicted that calving event is unlikely due to the absence of any significant rifting or structural damage. The context of calving is missing in the introduction section, such as what could be the earlier indicators of calving events and how do we predict calving.

- Line 139-140: Could you make the scales of subplots of Figure 2 consistent to clearly show the information?

- Line 147-148: Are the rifts a indicator of calving events? Can you discuss more about the formation and development of the rifts? From Figure 2 it's hard for me to see.

- Line 151: 'Fid. 2d' $\rightarrow$ 'Fig. 2d'

- Line 159-161: In year 1984 there is a calving event. Do you think that could be one of the reasons that the speed-up is much higher between 1972-74 and 1989 while between 1989 and 2016-17 is slower?

- Line 180-182: Could you have another layer of ice flow magnitude and directions (arrows like Figure 5) on top to show the divergence of the ice flow?

- Line 202-204: 'Ice rheology is assumed to...' $\rightarrow$ 'The relationship between creep and stress is assumed to...'

- Section 4.1: Modelling work is done to understand the acceleration/slowing down of the observed ice flow. Therefore, I think it's essential to at least show the momentum equations implemented by the ice sheet model, where the readers 
could clearly see how ice geometry, basal sliding and ice rheology influence the velocity field.

- Section 4.2: The experiments are diagnostic based on the ice geometry from 2009 and the reconstructed ice geometry from 1972, is that right? This should be clarified.

- Experiment (i): The authors modified the ice-shelf thickness with an annual rate. How about the grounded ice upstream from the ice shelf? Are they kept the same between the two simulation years? Will it cause a dramatic thickness change near the grounding line in 1972? Or is there an interpolation done? Please describe your method. Could you show the geometry difference between the two simulations somewhere in the figures?

- Experiment (ii): I think it's not appropriate to call this experiment 'grounding line retreat', because grounding line retreat is impossible without ice geometry change. This experiment adjust the bedrock to have grounding line at a different location. How much uplifting is needed? Normally the bedrock won't have significant change in short term. The difference of velocity comes from additional basal friction in the uplifted region. This experiment actually shows the sensitivity of velocity field to the basal sliding near the grounding line.

- Experiment (iii): It's mentioned in the abstract and the discussion section that the unpinning of ice from Chugunov Island is due to the calving event. From Fig. $4 \mathrm{~d}$, e, and also mentioned in the results section, the ice around Chugunov Island might be heavily damaged, leading to unpinning/debuttressing. The calving effect and the damage effect could be simulated by changing the ice front or modify the rate factor ' $A$ '. Why did the authors decide to evaluate the unpinning effect by changing bedrock? Furthermore, how much do you need to change to have the proper unpinning effect?

Printer-friendly version

Discussion paper 
- Line 267: E1 is Fig. 5b, not Fig. 5a.

- Line 281: 'experiment 5' $\rightarrow$ 'experiment E5' or 'E5' same for the other experiments there after.

- Line 286-288: Can you explain why the acceleration on the ice shelf is much higher than the grounding line (Fig. 5a) but all simulations show the opposite pattern?

- Line 361: 'E3; Fig. 5e' $\rightarrow$ 'E3; Fig. 5d'?

- Line 362: 'E4; Fig.5d' $\rightarrow$ 'Fig. 5a'?

- Line 367: 'E4; Fig. 5d' $\rightarrow$ 'E4; Fig. 5e'?

- Line 379-381: Could the authors add the simulation of calving event by simply change the ice front position and evaluate its influence on ice velocity?

- Line 433: 'hydrofracturing' $\rightarrow$ 'hydrofracturing.'

- Line 447: Morlighem et al., 2019 is not in the reference list.

- Figure 1: Could the authors add the transection of the geometry along a flow line to clearly show the retrograde bed? Maybe show the perturbation of bedrock in experiment (ii) in the same plot. Point out the position of Chugunov Island.

- Figure 2: The subfigures are oriented in different ways, and with different scales, making it hard to compare the size of ice bergs, the development of rifts and so on. Could you have a zoom out subfigure like Figure $1 \mathrm{~b}$ and put the boxes on top to show the zoom in area of the subfigures?

- Figure 4: Could you add a layer of velocity (magnitude and direction) on top of the satellite images to show the change of ice flow? That will make the figure more self-explanatory. 
- Figure 5: I think there should be a grounding line contour at the pinning point Chugunov Island.

- Figure S2: Could you have a subfigure of simulated velocity? And also please show the location of the grounding line. 